\title{
Shape optimization of geotextile tubes for sandy beach protection
}

\author{
Damien Isebe ${ }^{\dagger, *}$ Pascal Azerad ${ }^{\dagger}$, Frederic Bouchette $^{b}$, \\ Benjamin Ivorra ${ }^{\natural}$ and Bijan Mohammadi ${ }^{\dagger}$. \\ $\dagger$ Institut de Mathématiques et de Modélisation de Montpellier, Université de Montpellier II, 34095 Montpellier, France \\ ${ }^{b}$ Montpellier Geosciences, Université de Montpellier II, 34095 Montpellier, France

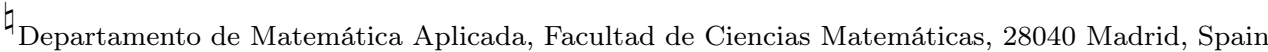 \\ Draft for IJNME
}

\begin{abstract}
The paper describes how to tackle new challenging coastal engineering problems related to beach erosion with a shape optimization approach. The method modifies the shape of the sea bottom in order to reduce beach erosion effects. Global optimization is shown to be necessary as the related functionals have several local minima. We describe the physical model used, the proposed protection devices against beach erosion and real case applications.
\end{abstract}

Keywords. Shape design, global optimization, water wave propagation, scattering, coastal engineering, beach erosion.

\section{Introduction}

Beach erosion problems bring increasing engineering demand. Indeed, about $70 \%$ of world beaches are crossing an erosion phase, $20 \%$ are stable and $10 \%$ show signs of fattening [1,2]. Obviously, this has major economical and environmental impacts. Groins, breakwaters and other coastal structures are used to decrease water wave energy or to control sediment flows. The shape of these devices are usually determined using simple hydrodynamical assumptions, structural strength laws or empirical considerations. However, as we will see, these are

*Email: isebe@math.univ-montp2.fr 
not fully satisfactory because of secondary effects. Our aim is to take advantage of shape optimization techniques, mainly used in aeronautics [3, 4], to propose new solutions to tackle this problem. This approach is fully innovative in coastal engineering.

Also, efficient global optimization algorithms are necessary to avoid the design to converge to local minima. Indeed, we will see that the related functionals have several local minima. Moreover, the search space is often non-connected. We use a semi-deterministic algorithm to allow global optimization of systems governed by PDEs with a low calculation complexity [5, 6].

The paper is structured as follows. In section 2, we recall the state of the art on geotextile tubes and we describe their parameterization. Section 3 presents the flow model used for the water waves propagation. Section 4 is dedicated to the description of the minimization problem. Finally, section 5 displays and discusses optimization results for two beach protection studies in Northwestern Mediterranean sea with the aim of reducing the energy available for sediment transport. In the Appendix, we briefly expose the optimization method used.

\section{Geotextile tubes and erosion process}

Water waves propagating toward the coast are characterized by their height $H$, their period $T$ and their direction $\theta$. The period does not change during the propagation but the direction and the height may vary when approaching emerged or submerged structures. This is mainly due to scattering phenomenon.

Knowing the height $H$ of the wave is crucial for the study of an erosion problem. Indeed, the suspension of sediments, produced by water wave action, is the main mechanism of erosion process. The suspension of sediments is essentially linked to the associated water wave mechanical energy $E=\frac{1}{8} \rho g H^{2}$ where $\rho$ is the water density and $g$ the gravity acceleration $[7,8,9]$.

Oceanographer observations of erosion show that the water waves can be roughly sorted in two categories according to their height $H$, below or above a critical value $H_{\text {lim }}$. Basically, those above $H_{\text {lim }}$, mainly present during storms, are erosive. They generate large mechanical energy. On the other hand, when $H<H_{\text {lim }}$, waves foster the reconstruction of eroded beaches. In that follows, the first class of water waves will be called erosive and the second class constructive.

In order to decrease water waves impact along the coastline many structures have been proposed $[10,11]$. Until recently the most used are emerged breakwaters or groins built with rocks or concrete. However, these techniques are expensive and only short-term solution for the beach protection because they mainly transfer in space the erosion process (figure 1 shows the negative impact of emerged groins on erosion. Accretion occurs only upstream from the longshore 
drift, whereas erosion is amplified downstream. Hence, it is soon necessary to build another groin further downstream... and so on).

Currently, interest goes to a new generation of soft structures having less impact on coastal hydro-sedimentary system $[12,13,14]$. These devices are geotextile tubes, also called geotubes (figure 2-Up). These geotubes are long cylinders made of synthetic textile and filled up with sand.

This paper discusses shape and location optimizations of geotubes for two sites both located on the Northwestern Mediterranean French coast.

The first analysis concerns the protection of a $2.4 \mathrm{~km}$ beach located between Sète and Agde [15] (figure 2-Down-(Left)). This is an large-scale industrial project under strict feasibility constraints. The Bas-Rhône Languedoc Company (BRL) is in charge of the device layout and installation. This company has a great experience of land-use management and development in Languedoc-Roussillon (a french area) in order to perform engineering studies and advisory services. Concerning the studied site, the coastal zone is characterized by a very low tidal excursion and moderate waves. This beach is subjected to severe erosion and the coastline has recorded a shoreward displacement of about $50 \mathrm{~m}$ since 1967 with a rate of shore retreat of about $1 \mathrm{~m} /$ year since 10 years [16]. In this spot, the critical wave height $H_{\text {lim }}$ is about $2 \mathrm{~m}$.

The second situation concerns the protection of the Le Grau du Roi Le Boucanet beach (figure 2-Down-(Right)). This problem leads to a higher dimension design problem, as we shall see below.

\subsection{Geotube parameterization}

Along the barred beach between Sète and Agde, the coastal topobathymetric profile includes two natural sandbars, created under the water wave action. An engineering preliminary study suggested first to restructure the beach and the two natural sandbars by sand recharging and secondly to place two geotubes side-byside behind the second natural sandbar in order to protect the new beach [15]. In the sequel, we model the two geotubes as a single one twice larger. Figure 3 shows a cross-section of the initial topobathymetry, the suggested sand recharging and the location of the two geotubes.

The initial topobathymetric data available for this study consists of series of echosounding data obtained from numerous monitorings since 2000 [16, 17]. So, we recreate exactly the real morphodynamic of the spot.

Geotubes will merely be represented by local modification of the topobathymetry. More precisely, in each node of the discrete domain we have a given value for the initial topobathymetry. To add a geotube arbitrarily in the domain, we parameterize its position using a series of $N$ control points in the domain. Cubic splines are used to connect these points. Once the location known, the 
shape (cross-section) of the geotube is given by a Gaussian function of the form $f(d)=H e^{-s d^{2}}$ where $d$ is the normal distance to the spline. This adds two additional parameters $(s, H)$ for the control of the height and width of the geotubes. Thus, we have in each node a modification of the topobathymetry (see figure 4) which accounts for the presence of the geotubes.

\section{Flow model}

The propagation of water waves over linear irregular bottom bathymetry and around islands involves many processes such that shoaling, refraction, energy dissipation and diffraction.

To compute the water wave propagation, we use the REF/DIF code $[18,19$, 20]. REF/DIF is a open source software designed for modelling wave propagation over a weakly varying seabottom. It takes into account both refraction and diffraction phenomena or wave attenuation. However, this model does not account for the reflection phenomenon. This appears, for instance, in water wave propagation in a harbor with vertical emergent structures. Our applications only concern propagation toward sandy beaches. The model has been validated on various experimental test cases [21, 22, 23].

$\mathrm{REF} / \mathrm{DIF}$ is based on a parabolic weakly nonlinear combined refraction and diffraction model which incorporates all of the effects mentioned above [24, 20]. This model combines the essential features of the two specific approaches, a mild slope model $[25,26,27,28]$ and a diffraction model $[29,30]$. In this section, we briefly present the nonlinear combined refraction/diffraction model.

\subsection{Nonlinear combined refraction/diffraction model}

Kirby \& Dalrymple, at the Center for Applied Coastal Research (University of Delaware, US), developed a general formulation governing waves in a domain with

slow but arbitrary depth variations $[24,31]$. The following parabolic approximation for refraction/diffraction is obtained,

$$
\begin{aligned}
2 i k C C_{g} \frac{\partial A}{\partial x} & +2 k\left(k-k_{0}\right)\left(C C_{g}\right) A+i A \frac{\partial\left(k C C_{g}\right)}{\partial x} \\
& +\frac{\partial\left(C C_{g} \frac{\partial A}{\partial y}\right)}{\partial y}-k\left(C C_{g}\right) K^{\prime}|A|^{2} A=0
\end{aligned}
$$

where

$$
C=\sqrt{\frac{g}{k} \tanh k h} \text { (phase speed), }
$$




$$
\begin{gathered}
C_{g}=C \frac{\left(1+\frac{2 k h}{\sinh 2 k h}\right)}{2} \text { (group velocity), } \\
K^{\prime}=k^{3}\left(\frac{C}{C_{g}}\right) \frac{\cosh 4 k h+8-2 \tanh ^{2} k h}{8 \sinh ^{4} k h},
\end{gathered}
$$

$h(x, y)$ is the local water depth and $g$ the gravity. The local wave number, $k(x, y)$, is related to the angular frequency of the waves, $\omega$, and the water depth $h$ by the nonlinear dispersion relationship

$$
\omega^{2}=g k \tanh k h \text {. }
$$

$k_{0}$ is a reference wave number related to the incoming condition. Equation (1) is valid under the mild slope assumption $\nabla h / k h<<1$ [24].

Equations (1) and (5) are numerically solved by an implicit finite difference method $[19,20]$ in a domain of size $[0, m r] \times[0, n r]$. We define $x_{i}=(i-1) * \Delta x$ and $y_{j}=(j-1) * \Delta y$ where $\Delta x$ and $\Delta y$ are the space steps on each directions. The axis $x=0$ is the offshore boundary where the incoming condition is prescribed. The water wave propagation is computed for the increasing $i$. The lateral boundaries $y=0$ and $y=n r$ have open boundary conditions. Concerning the topobathymetry, at each node $(i, j)$ of the grid, we have a positive value $h(i, j)$ corresponding to the water depth.

In the model (1), $A=A(x, y)$ is the complex amplitude related to the water surface displacement by

$$
\eta(x, y)=\Re\left(A(x, y) e^{i k x}\right) .
$$

\section{Cost function}

An optimization problem refers to the minimization of a cost function $J$, also called objective function (see the Appendix). In this study, our aim is to optimize the shape of a given geotube and its distance to the coast in order to minimize the energy available for sediment transport in the near-shore zone. We have seen in section 2 that this cost function can be expressed as a function of the water wave mechanical energy $E=\frac{1}{8} \rho g H^{2}$ where $\rho$ is the water density and $H=2 A$ $[7,8]$. This energy is crucial in the erosion process as it fosters the motion of sediments.

Another important issue for the modified geometry (i.e. after addition of the geotube) is that the geotube should not increase the sea bottom fluid particle velocity $^{1}$ shoreward. For a water wave propagation in the x-direction, the stationary

\footnotetext{
${ }^{1}$ Also called bottom orbital velocity
} 
bottom orbital velocity $U_{\text {orb }}$ is given by [30]

$$
U_{\text {orb }}=\frac{A g k}{\omega} \cos \mathbf{k} \cdot \mathbf{x}
$$

with $\mathbf{x}=(x, y)$ and $\mathbf{k}=k(\cos \theta, \sin \theta)$ where $k$ is the wave number and $\theta$ the wave direction.

However, section 2 and Table 1 suggest two main categories of water waves: the constructive and the erosive ones which, as we said, correspond to waves with heights below and above the critical water height $H_{\text {lim }}=2$ meters. Hence, for a given direction of propagation $\theta$, the following cost function is considered

$J_{\theta}=\frac{\int_{D} E_{H>H_{l i m}} d S}{\int_{D} E_{H<H_{l i m}} d S}+\left(\left\|U_{\text {orb }}\right\|-\left\|U_{\text {orb }}^{\text {initial }}\right\|\right)_{+}+\left(\int_{D} E_{H<H_{l i m}} d S-\int_{D} E_{H<H_{l i m}}^{\text {initial }} d S\right)_{+}$

where $(x)_{+}=\max (x, 0)$ is any regularized max operator in order to have $J_{\theta}$ differentiable and initial is related to the initial unmodified sea bottom. $D$ is the area where the minimization is desirable. The first term of $J$ aims to maximize the constructive waves and minimize destructive ones (as a low-pass filter for waves). The second (resp. third) term penalizes orbital velocity energy (resp. energy produced by constructive waves) greater than their initial values (i.e. for the unperturbed region).

As we are interested by multi-point optimization, we consider the following weighted combination

$$
J=\sum p_{\theta} J_{\theta}
$$

where $p_{\theta}$ is the observation frequency for a given wave direction. This last point again brings the importance of global minimization tools.

This is also clear from figure 5 which shows a sampling of the functional $J$ along one dimension for a situation where the only parameter is the distance of the geotube to the beach. The area $D$ where functional $J$ is computed lies between 100 and 250 meters far from the coastline. The height of the geotube has been set to $3 \mathrm{~m}$, its width to $12 \mathrm{~m}$ and the offshore distance sampled between 100 and $750 \mathrm{~m}$ seaward for a simple straight geotube. The minimum is obtained for a geotube located at around $350 \mathrm{~m}$ from the coastline (we come back to this simulation in section 5).

\section{Application to beach erosion control}

In this section we apply the optimization algorithm (briefly described in the Appendix) to PDE based shape optimization problems arising in the design of beach protection device. We consider two different sites where the beach is either straight or curved (see figure 2). 


\subsection{Straight geotube}

We first design a straight geotube. This problem arises in the protection of a beach located between Sète and Agde (Northwestern Mediterranean sea, LanguedocRoussillon, France) where industrial constraints reduce the number of design parameters to two: the distance from the coast and the height of the tube. The computational domain for the flow is $2400 \mathrm{~m}$ longshore and $1200 \mathrm{~m}$ shoreward. The mesh size is $1 \mathrm{~m}$ cross-shore and $5 \mathrm{~m}$ longshore. The tube is of the same length as the studied costal zone. In that case, as the tube was already predesigned, the width is fixed to $12 \mathrm{~m}$. The propagation is performed for water waves data available at $1.2 \mathrm{~km}$ of the coastline, stemming from French National Center Archive for In Situ Wave Data (e.g. from table 1). Recreational sailing and tourism navigation constraints due to local topobathymetry imply that the search space $[100 \mathrm{~m}, 200 \mathrm{~m}] \cup[300 \mathrm{~m}, 850 \mathrm{~m}]$ is disconnected. This because no tube should be placed on the second natural sandy bar (see figure 3) to keep a minimum depth of $2 \mathrm{~m}$. Coastal engineering suggests to build devices to control the energy generated in the area between 100 and 250 meters far from the coastline (denoted by $D$ in the cost function definition, see section 4 ). This zone corresponds to the gap between the first and the second natural sand bar.

Coastal engineering first guess would suggest to set the geotextile tube around $550 \mathrm{~m}$ from the coast to recreate the third natural sand bar which is missing in this site. Available geotubes are $3 \mathrm{~m}$ high which leaves an acceptable depth of water to float ships. The optimization procedure locates the geotube at 353 $\mathrm{m}$ far from the coast with a height of $2.5 \mathrm{~m}$. This result is confirmed by the sampling of figure 5. For this reduced number of parameters, which was imposed by industrial constraints, we could have manually searched the design space. But we preferred to test our optimizer on this case for which the cost function $J$ is clearly non-convex and possesses several local minima (see figure 5).

Table 2 shows that the optimized geotube is inactive for the constructive water waves and reduces the erosive ones. In addition, because of the multi-

point problem considered, this is true for all studied propagation directions : the geotube plays its low-pass filter role.

Global functional histories for the current and best element found are shown in figure 6. We plot the output of the core minimization algorithm for different initializations provided by our multi-layer construction. Several local attraction basins have been visited. The core minimization algorithm has been called about 50 times. Overall the optimization has required about 700 functional evaluations. Each state evaluation requires about 15 min on a (3 GHz - 1 GB) personal computer. Figure 7 shows the water wave height for the protected and unprotected beaches for erosive SSE condition (See Table 1).

This shows that a geotube set immediately before the second natural sand bar 
makes it possible to break the water waves, therefore attenuating their energy in the nearshore zone. More precisely, this study reveals that the geotube must break the water waves sufficiently far away from the coastline but not too far, otherwise the wave recreates itself. In addition, figure 8 ensures that this optimized configuration does not increase the bottom orbital velocity compared to the initial configuration, which guarantees that bottom shear-stress is not amplified (see section 4).

\subsection{Curved geotube}

The topobathymetry is the one of Le Grau du Roi Le Boucanet beach (Northwestern Mediterranean sea, Languedoc-Roussillon, France). The studied area corresponds to a $3 \mathrm{~km}$ longshore and $4.4 \mathrm{~km}$ seaward zone with a mesh size of $5 \mathrm{~m}$. We consider the design of one geotube defined by 8 control parameters. A spline is defined passing by 3 nodes (this makes 6 parameters). The two remaining parameters are height and width of the tubes, which are let free as well. The length of the tube is required to remain between $500 \mathrm{~m}$ and $2000 \mathrm{~m}$.

The cost function (8) is minimized in the region $D$, which lies between 100 et $250 \mathrm{~m}$ offshore, depicted in figure 9-(Left). For computation time reasons, we only consider a mono-directional south incident water wave with a period $\mathrm{T}=8$ s and an amplitude $\mathrm{A}=3 \mathrm{~m}$.

The optimized geotextile tube is $1.5 \mathrm{~km}$ long with a height of $13 \mathrm{~m}$ and a width of $70 \mathrm{~m}$. Its location is represented in figure 9-(Right). This optimized configuration reduces drastically the energy available for sediment transport. In this case, the cost function decreases by more than $65 \%$ compared to the unmodified topobathymetry. In practice, it is obvious that putting this optimized geotube into construction won't be easy, owing to its size. But in this section, the objective is to highlight the efficiency of the global optimization algorithm.

We display in figure 10 the water height $H$ in the whole domain for the two configurations. We observe that, in the region $D$ (close to the east coast), the water height is reduced from $2 \mathrm{~m}$ to $1 \mathrm{~m}$ by the use of the optimized geotextile tube. Also, we observe an important decrease of the bottom orbital velocity in the optimized configuration (see figure 11). This is important to reduce sand suspension and displacement by water waves. Finally, free surface elevation is clearly reduced in region $D$ after geotube introduction (see figure 12).

\section{Conclusion}

A coastal engineering problem has been modelled and optimal shape design performed for sandy beach protection. Results have shown that geotubes can be designed to reduce beach erosion, under the constraint of minimum water draught 
for coastal navigation. These devices permit reduction of wave energy, orbital velocity and free surface elevation. Finally, complementary studies have shown that despite not being accounted for during design, the generated currents [32] are also lower after the introduction of the protection device.

\section{Acknowledgements}

This work is part of the COPTER research project (2006-2009) NT05 - 2-42253, supported by the French National Research Agency. The authors would like to thank the Bas-Rhône Languedoc Engineering Co. for their feedbacks during this work realization.

\section{References}

[1] R. Paskoff. Côtes en danger. Ed. Masson., 1993.

[2] R. Paskoff. Les plages vont-elles disparaître? Le Pommier, 2006.

[3] B. Mohammadi and O. Pironneau. Applied shape optimisation for fluids. Oxford University Press, 2001.

[4] A. Jameson, F. Austin, M.J. Rossi, W. Van Nostrand, and Knowles G. Static shape control for adaptive wings. AIAA Journal, 32(9):1895-1901, 1994.

[5] B. Ivorra. Optimisation globale semi-déterministe et applications industrielles. PhD Thesis. Université de Montpellier 2, 2006.

[6] B. Ivorra, B. Mohammadi, D.E. Hertzog, and J.G. Santiago. Semideterministic and genetic algorithms for global optimization of microfluidic protein-folding devices. International Journal for Numerical Methods in Engineering, 66(2):319-333, 2006.

[7] C.C. Mei. The applied dynamics of ocean surface waves. Vol I. World Scientific Publishing, 1989.

[8] R.G. Dean and R.A. Dalrymple. Water Wave Mechanics for Engineers and Scientists. Vol 2. World Scientific Publishing, 1991.

[9] R.G. Dean and R.A. Dalrymple. Coastal processes with Engineering Applications. Cambridge University Press, 2004. 
[10] du Territoire et de l'Environnement Ministère de l'Aménagement. La défense des côtes contre l'érosion marine. Pour une approche globale et environnementale. 1997.

[11] Ramoge. La défense des plages contre l'érosion. Guide à l'attention des maîtres d'ouvrages. www.ramoge.org, 2002.

[12] R. Tomlinson, J. McGrath, L.A. Jackson, and I. Tuner. Monitoring of a multi-functional submerged geotextile reef breakwater. Proc. 28th International Conference on Coastal Engineering, pages 1923-1935, 2002.

[13] R. Ranasinghe and I.L Turner. Shoreline response to submerged structures: a review. Coastal Engineering, pages 536:65-79, 2006.

[14] R. Archetti, M. Kramer, D. Paphitis, C. Mosso, A. Lamberti, and M. Di Risio. European experience of low crested structures for coastal management. Coastal Engineering, pages 52:841-866, 2005.

[15] N. Fraysse. Aménagement du lido de sète à marseillan. protection de la partie nord du lido: étude comparative de solution. Technical report, Bas-Rhône Languedoc Ingénierie, 2006.

[16] R. Certain. Morphodynamique d'une côte sableuse microtidale à barres: le golfe du lion (languedoc-roussillon). PhD Thesis, Université de Perpignan, pages 1-209, 2002.

[17] S. Meulé, V. Rey, R. Certain, and C. Pinazo. Wave transformation on a microtidal barred beach (sète,france). Journal of Marine System, pages 38:19$34,2005$.

[18] J. T. Kirby and R. A. Dalrymple. Combined refraction/diffraction model ref/dif 1, user's manual. Coastal and Offshore Engineering and Research, Inc., Newark, DE., January, 1985. (Revised June, 1986).

[19] J. T. Kirby and R. A. Dalrymple. Combined refraction/diffraction model ref/dif 1, version 2.5. documentation and user's manual. Research Report No. CACR-94-22, Center for Applied Coastal Research, Department of Civil Engineering, University of Delaware, Newark., 1994.

[20] J. T. Kirby and R. A. Dalrymple. Refdif1 v2.5 refraction diffraction model. Technical report, CACR. Short A.D 1999. Beach and Shoreface Morphodynamics., Wiley:380pp, 1995. 
[21] P.A. Work and J.M. Kaihatu. Wave transformation at pensacola pass, florida. Journal of Waterway, Port, Coastal and Ocean Engineering, 123:314321, 1997.

[22] A. Chawla, H.T. Ozkan-Haller, and J. T. Kirby. Spectral model for wave transformation over irregular bathymetry. Journal of Waterway, Port, Coastal and Ocean Engineering, 124:189-198, 1998.

[23] A. W. Raichle. Numerical predictions of surfing conditions at mavericks, california. Shore and Beach, 66(2):26-30, 1998.

[24] J. T. Kirby and R. A. Dalrymple. A parabolic equation for the combined refraction diffraction of stokes waves by mildly varying topography. J. Fluid. Mechanics., 136:443-466, 1983.

[25] J. C. W. Berkhoff. Computation of combined refraction-diffraction. In ASCE., editor, Proc. 13th Coastal Eng. Conf., Vancouver, pages 471-490, 1972 .

[26] A. C. Radder. On the parabolic equation method for water-wave propagation. Journal of Fluid Mechanics, 95(1):159-176, 1979.

[27] I.G. Jonsson and O. Skovgaard. A mild-slope wave equation and its application to tsunami calculations. Mar. Geodesy, 2:41-58, 1979.

[28] N. Booij. A note on the accuracy of the mild slope equation. Coastal Engineering, 7:191-203, 1983.

[29] C.C. Mei and D.K.P. Yue. Forward diffraction of stokes waves by a thin wedge. J. Fluid Mech., 99(1):33-52, 1980.

[30] C.C. Mei and E.O. Tuck. Forward scattering by long thin bodies. SIAM J. Appl. Math., 39(1):178-191, 1980.

[31] J. T. Kirby and R. A. Dalrymple. Verification of a parabolic equation for propagation of weakly-nonlinear waves. Coastal Engineering., 8:219-232, 1984.

[32] D. Isèbe, F. Bouchette, P. Azerad, B. Ivorra, B. Mohammadi, and R. Certain. An introduction to the design of beach defence structures by numerical shape optimization. In preparation, 2006.

[33] B. Mohammadi and J-H. Saiac. Pratique de la simulation numérique. Dunod, 2003. 
[34] B. Ivorra, B. Mohammadi, L. Dumas, P. Redont, and O. Durand. Semideterministic vs. genetic algorithms for global optimization of multichannel optical filters. International Journal of Computational Science and Engineering, 2(3):170-178, 2006.

[35] L. Debiane, B. Ivorra, B. Mohammadi, F. Nicoud, T. Poinsot, A. Ern, and H. Pitsch. A low-complexity global optimization algorithm for temperature and pollution control of a complex chemistry flame. International Journal of Computational Fluid Dynamics, 20(2):93-98, 2006.

[36] B. Ivorra, A.M. Ramos Del Olmo, and B. Mohammadi. A semi-deterministic global optimization method. application to a control problem of the burger equation, comparing with other methods. Journal of Optimization Theory and Applications, 135(1), 2007.

\section{A Optimization method}

In this appendix, we briefly present the global optimization method used for the applications.

We consider the following minimization problem

$$
\min _{x \in \Omega} J(x)
$$

where $J: \Omega \rightarrow \mathbb{R}$ is the cost function, $x$ is the optimization parameter belonging to an admissible space $\Omega \subset \mathbb{R}^{N}$, with $N \in \mathbb{N}$. Replacing $J$ by $J-J_{\text {min }}$, where $J_{\text {min }}$ is the minimum of $J$, we can assume that $\min _{x \in \Omega} J(x)=0$.

In this section, we give a short presentation of an original global optimization method used to solve (10) (a full description can be found in [5]):

Consider any optimization algorithm (gradient, Newton, etc...) to solve (10). This we call core optimization algorithm. It has an output denoted by $A_{0}\left(v_{0}, N_{0}, \varepsilon\right) \in$ $\Omega$ where $v_{0} \in \Omega$ is one of its initial condition, $N_{0} \in \mathbb{N}^{+}$is the number of iterations and $\varepsilon \in \mathbb{R}$ defining the stopping criterion. The parameters $N_{0}$ and $\varepsilon$ are fixed at the beginning of the optimization process. In the sequel, we denote $A_{0}\left(v_{0}, N_{0}, \varepsilon\right)$ by $A_{0}\left(v_{0}\right)$.

We assume that there exists an initial condition $v_{\varepsilon} \in \Omega$ such that $A_{0}\left(v_{\varepsilon}\right)$ approximate the solution of (10) with a precision $\varepsilon \in \mathbb{R}^{+}$. The general idea of the optimization method presented here is to improve the efficiency of any particular core optimization algorithm $A_{0}$ by making it global. So, we consider that the minimization problem is solved if and only if the initial condition $v_{0}$ lies in the global minimum attraction basin of $J$. To find such an initial condition, we 
consider $v_{0}=s$ as a new variable and solve the following optimization problem, which is a reformulation of (10),

$$
\min _{s \in \Omega} J\left(A_{0}(s)\right)
$$

To perform the minimization (11), we propose to use a two-layer semi-deterministic algorithm (here, we use the simplified notation SDA) based on the secant method [33].

The first layer algorithm $A_{1}\left(v_{1}, N_{1}, \varepsilon\right)$, where the number of iterations $N_{1} \in$ $\mathbb{N}^{+}$is fixed, requests the algorithm $A_{0}$. It reads:

- Input: $v_{1}, N_{1}, \varepsilon$

- $v_{2}$ chosen randomly

For $i$ going from 1 to $N_{1}$

- $o_{i}=A_{0}\left(v_{i}\right)$

- $o_{i+1}=A_{0}\left(v_{i+1}\right)$

- If $J\left(o_{i}\right)=J\left(o_{i+1}\right)$ EndFor

- If $\min \left\{J\left(o_{k}\right)_{k=1, \ldots, i}\right\}<\varepsilon$

EndFor

- $v_{i+2}=v_{i+1}-J\left(o_{i+1}\right) \frac{v_{i+1}-v_{i}}{J\left(o_{i+1}\right)-J\left(o_{i}\right)}$

EndFor

- Output: $A_{1}\left(v_{1}, N_{1}, \varepsilon\right):=\operatorname{argmin}\left\{J\left(o_{k}\right), k=1, \ldots, i\right\}$

Note that the step $v_{i+2}=v_{i+1}-J\left(o_{i+1}\right) \frac{v_{i+1}-v_{i}}{J\left(o_{i+1}\right)-J\left(o_{i}\right)}$ is the secant method applied to the new functional $v \mapsto J\left(A_{0}(v)\right)$.

However, as this line search minimization algorithm might fail, an external level $A_{2}$ is added to the algorithm $A_{1}$ to have a multidimensional search. Hence, $v_{1}=w$ is seen as a new variable in $A_{1}$ and solve the following optimization problem, which is a reformulation of (11),

$$
\min _{w \in \Omega} J\left(A_{1}(w)\right)
$$

To perform the minimization (12), we consider a two-layer algorithm, with an output called $A_{2}\left(w_{1}, N_{2}, \varepsilon\right)$, where the number of iterations $N_{2} \in \mathbb{N}^{+}$is fixed, which calls algorithm $A_{1}$ (which in turn calls $A_{0}$ ). It reads:

- Input: $w_{1}, N_{2}, \varepsilon$

- $w_{2}$ chosen randomly

For $i$ going from 1 to $N_{2}$

- $p_{i}=A_{1}\left(w_{i}\right)$

- $p_{i+1}=A_{1}\left(w_{i+1}\right)$ 
- If $J\left(p_{i}\right)=J\left(p_{i+1}\right)$ EndFor

- If $\min \left\{J\left(p_{k}\right)_{k=1, \ldots, i}\right\}<\varepsilon$ EndFor

- $w_{i+2}=w_{i+1}-J\left(p_{i+1}\right) \frac{w_{i+1}-w_{i}}{J\left(p_{i+1}\right)-J\left(p_{i}\right)}$

EndFor

- Output: $A_{2}\left(w_{1}, N_{2}, \varepsilon\right):=\operatorname{argmin}\left\{J\left(p_{k}\right), k=1, \ldots, i\right\}$

Again, the step $w_{i+2}=w_{i+1}-J\left(p_{i+1}\right) \frac{w_{i+1}-w_{i}}{J\left(p_{i+1}\right)-J\left(p_{i}\right)}$ is the secant method applied to the new functional $w \mapsto J\left(A_{1}(w)\right)$.

In practice, we randomly choose the initial condition $w_{1} \in \Omega$ and we consider $\left(N_{0}, N_{1}, N_{2}\right)=(10,5,5)$. These values give a good compromise between computation complexity and result accuracy. This algorithm was first described in [33], along with mathematical background. It has been validated on various benchmark test cases [5] and industrial applications [6, 34, 35, 36].

\begin{tabular}{|c|c|c|c|c|}
\hline & South & South South East & East South East & East \\
\hline \hline constructive & $H_{s}=0.76 \mathrm{~m}$ & $H_{s}=0.85 \mathrm{~m}$ & $H_{s}=0.85 \mathrm{~m}$ & $H_{s}=0.66 \mathrm{~m}$ \\
water & $T_{s}=4.96 \mathrm{~s}$ & $T_{s}=5.21 \mathrm{~s}$ & $T_{s}=5.21 \mathrm{~s}$ & $T_{s}=4.99 \mathrm{~s}$ \\
waves & $p=24.66 \%$ & $p=22.75 \%$ & $p=22.75 \%$ & $p=17.5 \%$ \\
\hline \hline erosive & $H_{s}=2.91 \mathrm{~m}$ & $H_{s}=3.233 \mathrm{~m}$ & $H_{s}=3.233 \mathrm{~m}$ & $H_{s}=3.55 \mathrm{~m}$ \\
water & $T_{s}=7.54 \mathrm{~s}$ & $T_{s}=7.78 \mathrm{~s}$ & $T_{s}=7.78 \mathrm{~s}$ & $T_{s}=8.03 \mathrm{~s}$ \\
waves & $p=2.84 \%$ & $p=3.25 \%$ & $p=3.25 \%$ & $p=2.5 \%$ \\
\hline
\end{tabular}

Table 1: Typical hydrodynamic data used in our simulations . Significative height $H_{s}$, mean period $T_{s}$ and mean frequency of observation $p$ for four significant directions of propagation. 


\begin{tabular}{|c|c|c|c|c|}
\hline & South & South South East & East South East & East \\
\hline \hline $\begin{array}{c}\text { constructive } \\
\text { water } \\
\text { waves }\end{array}$ & $==$ & $==$ & $==$ \\
\hline weights & $24.66 \%$ & $22.75 \%$ & $22.75 \%$ & $17.5 \%$ \\
\hline \hline $\begin{array}{c}\text { erosive } \\
\text { water } \\
\text { waves }\end{array}$ & $15 \%$ gain & $30 \%$ gain & $16 \%$ gain & $15 \%$ gain \\
\hline weights & $2.84 \%$ & $3.25 \%$ & $3.25 \%$ & $2.5 \%$ \\
\hline \hline overall gain & \multicolumn{4}{|c|}{$23 \%$} \\
\hline
\end{tabular}

Table 2: Multi-point optimization: variations of constructive and destructive energies for various incidences $\theta . \quad(==)$ means that the quantity is almost unchanged, less than $0.1 \%$ variation.

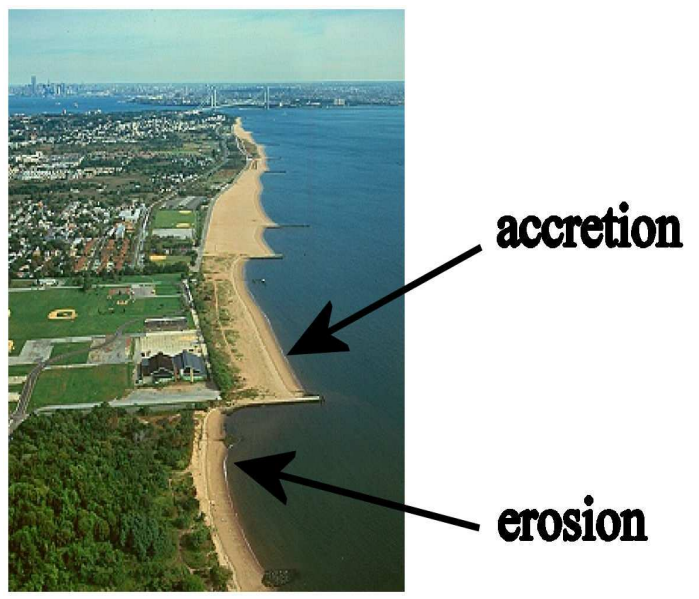

Figure 1: Secondary effect of emerged groins: erosion has been amplified on one side of the groins (downstream from the longshore drift). 

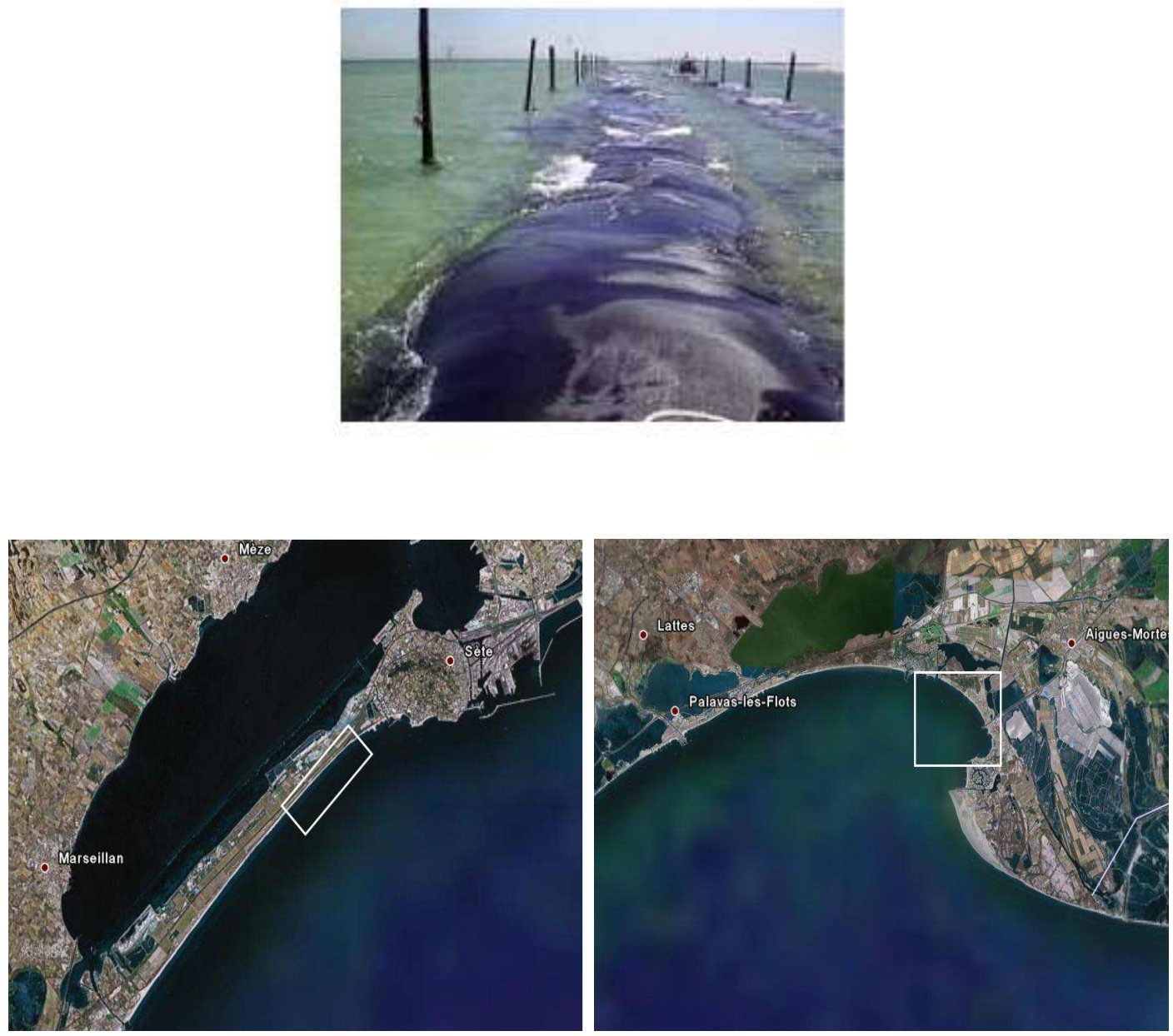

Figure 2: Up- A geotextile tube before submersion (source: BRL engineering); Down- Left: the barred beach between Sète and Agde, Right: the beach of Le Grau du Roi Le Boucanet (source: Google Earth). 


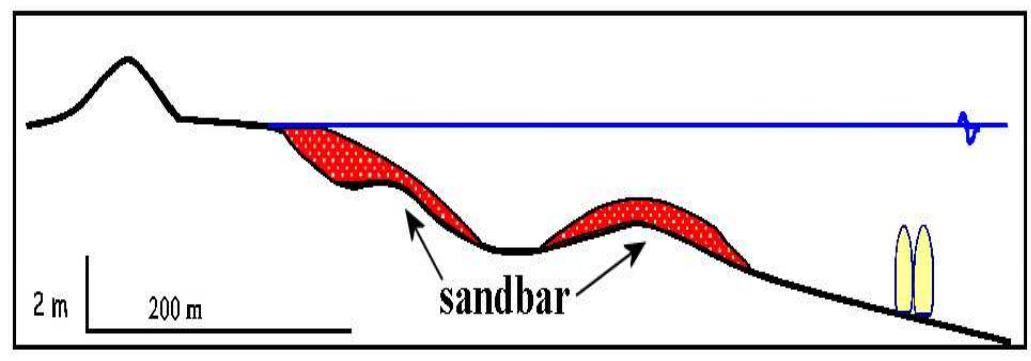

\section{sand recharging}

Mgeotextile tubes

Figure 3: The improvement of the considered site (source: BRL engineering).
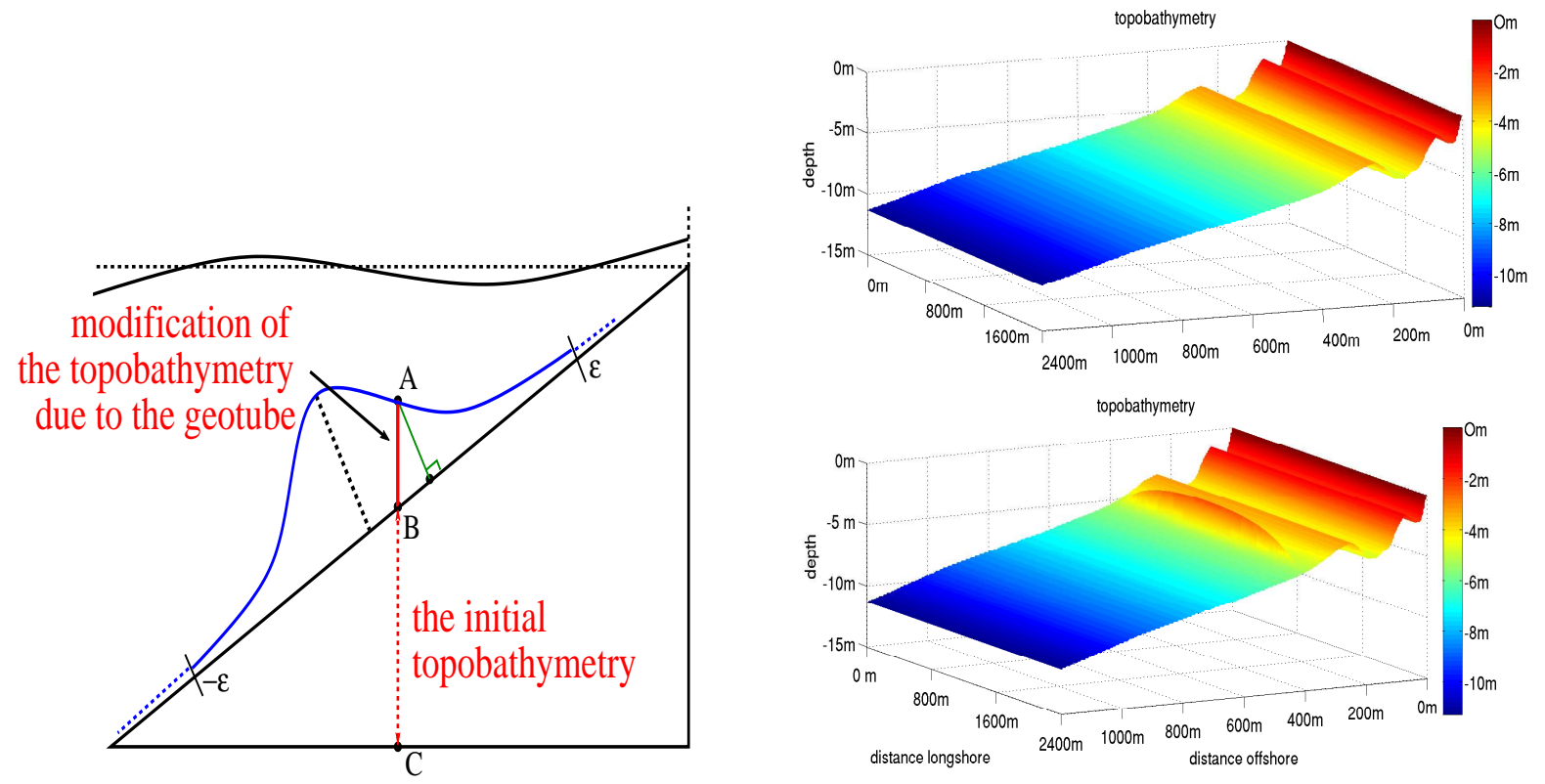

Figure 4: Left: The profile parameterization for the geotube in an academic linear topography; Right: Up- The initial topobathymetry of the barred beach, Down- Implementation of a geotube in the topobathymetry. Note that both ends are smoothed by a suitable function. 


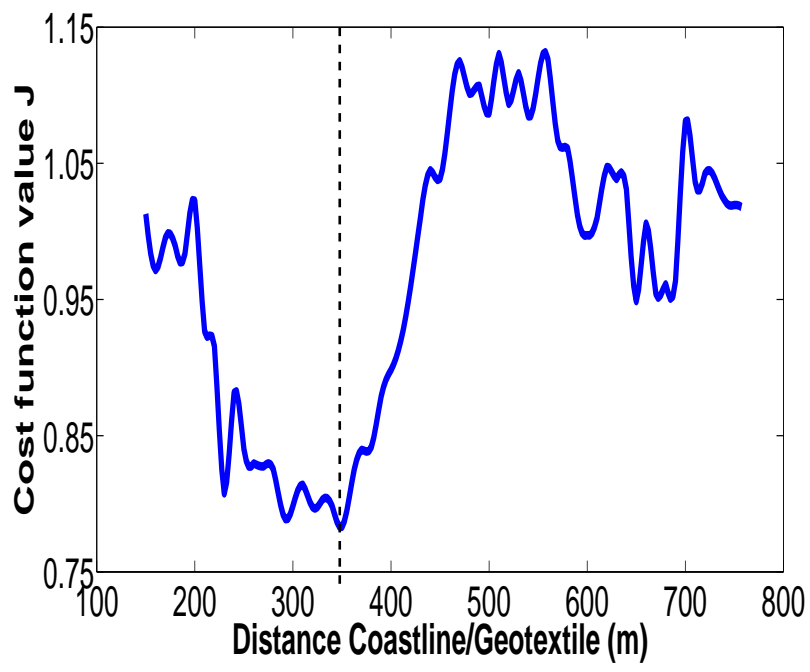

Figure 5: Cost function evolution w.r.t to the geotube position. This is difficult to solve with a local minimization algorithm.

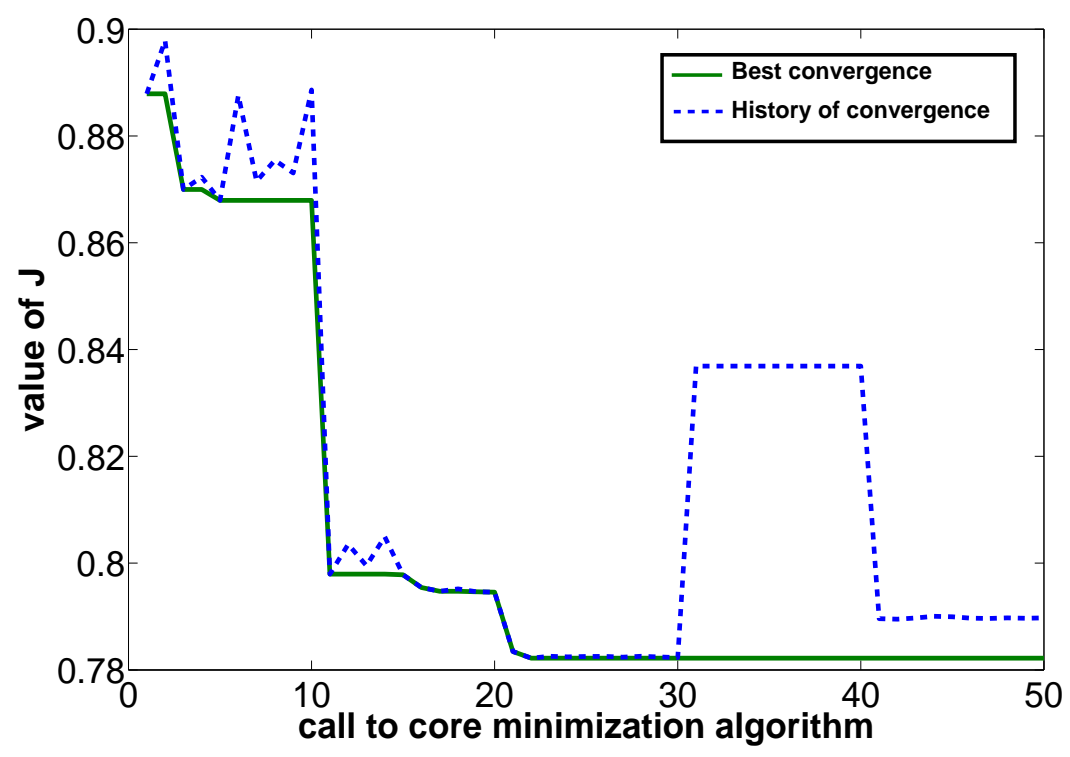

Figure 6: Functional values history for the best element found by the core minimization algorithm and the current value of the functional. One sees that the optimization algorithm is not a descent method. 


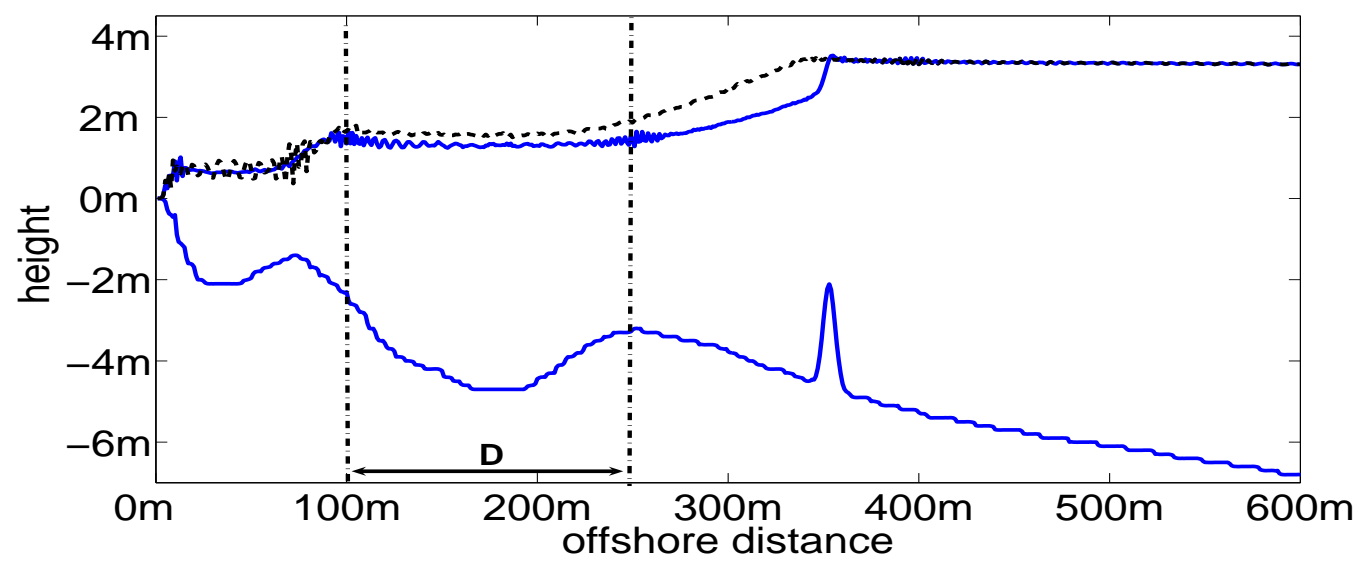

Figure 7: Bottom curve: cross-shore topobathymetry. Solid top curve: water height compared to the original height (dashed line).

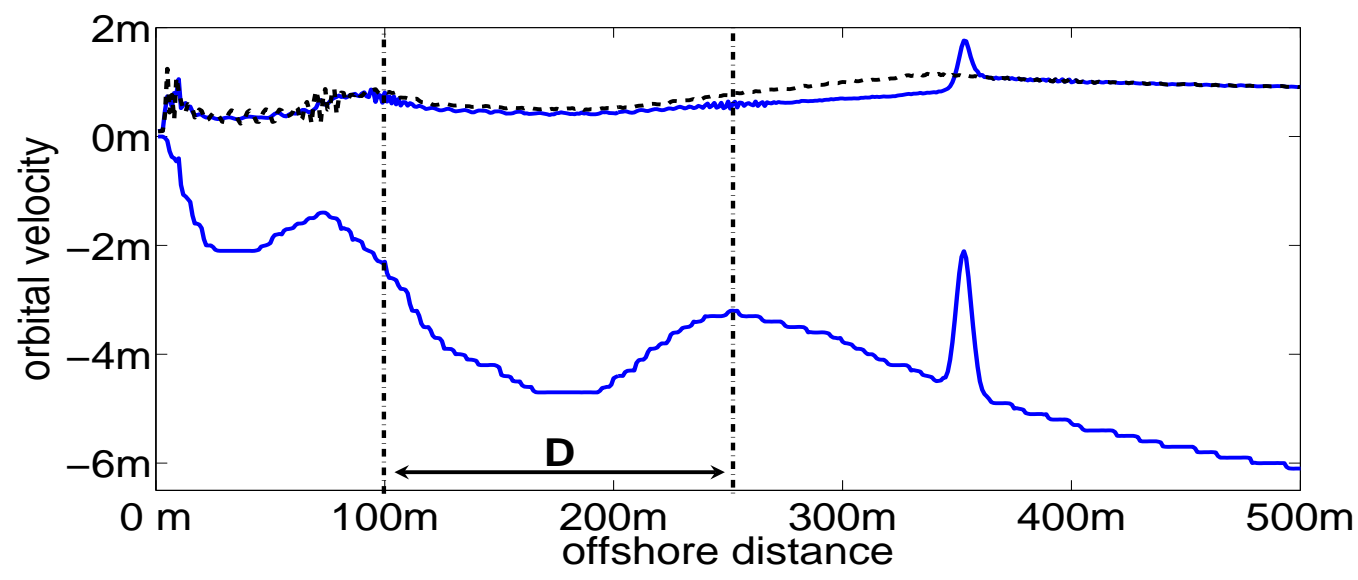

Figure 8: Bottom curve: cross-shore topobathymetry. Solid top curve: orbital velocity compared to the velocity on the unprotected beach (dashed line). 

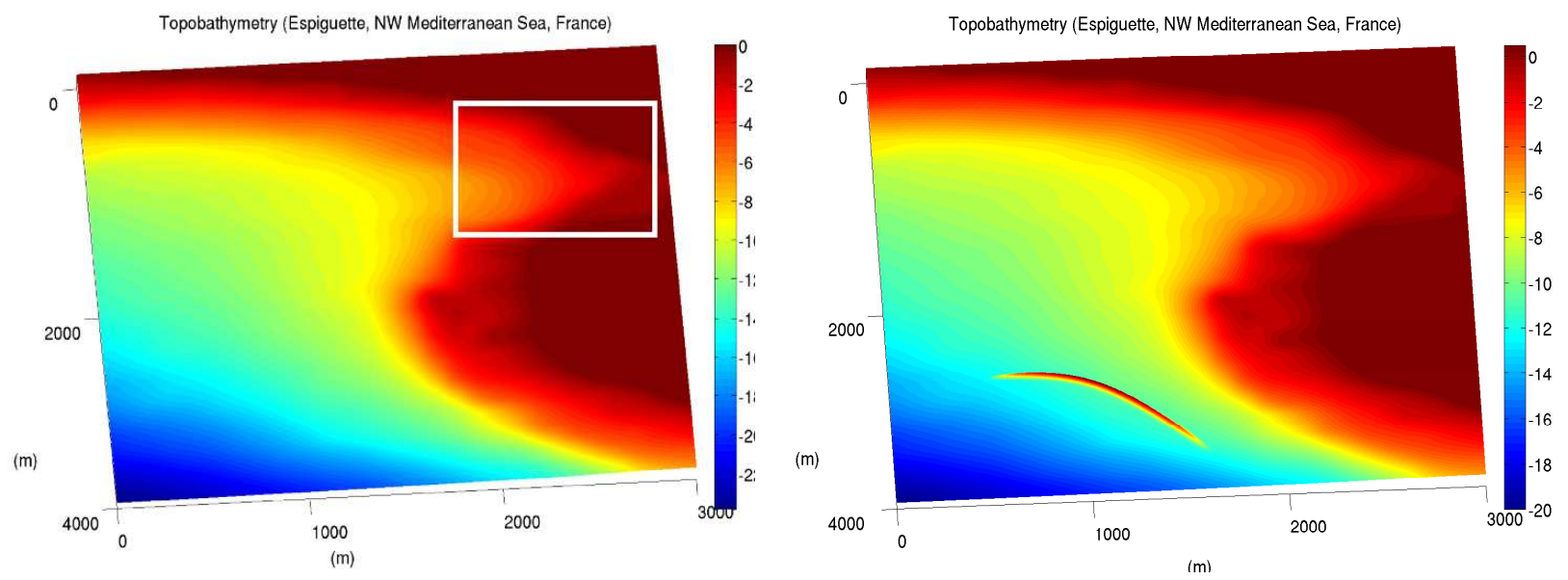

Figure 9: (Left): The initial topobathymetry where the white box represents the region $D$ for the cost function computation; (Right): The modified topobathymetry with the optimized geotube.
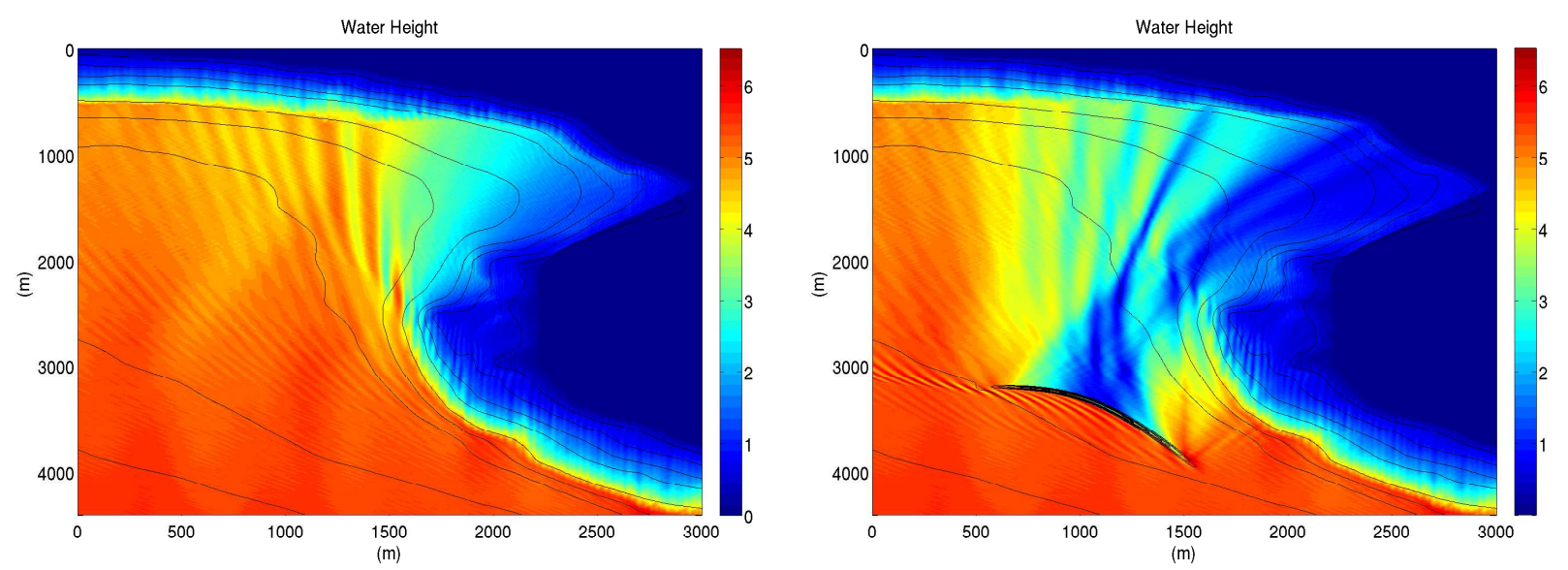

Figure 10: The water height $H$ in the whole domain: (Left) for the initial configuration, (Right) for the optimized configuration. 

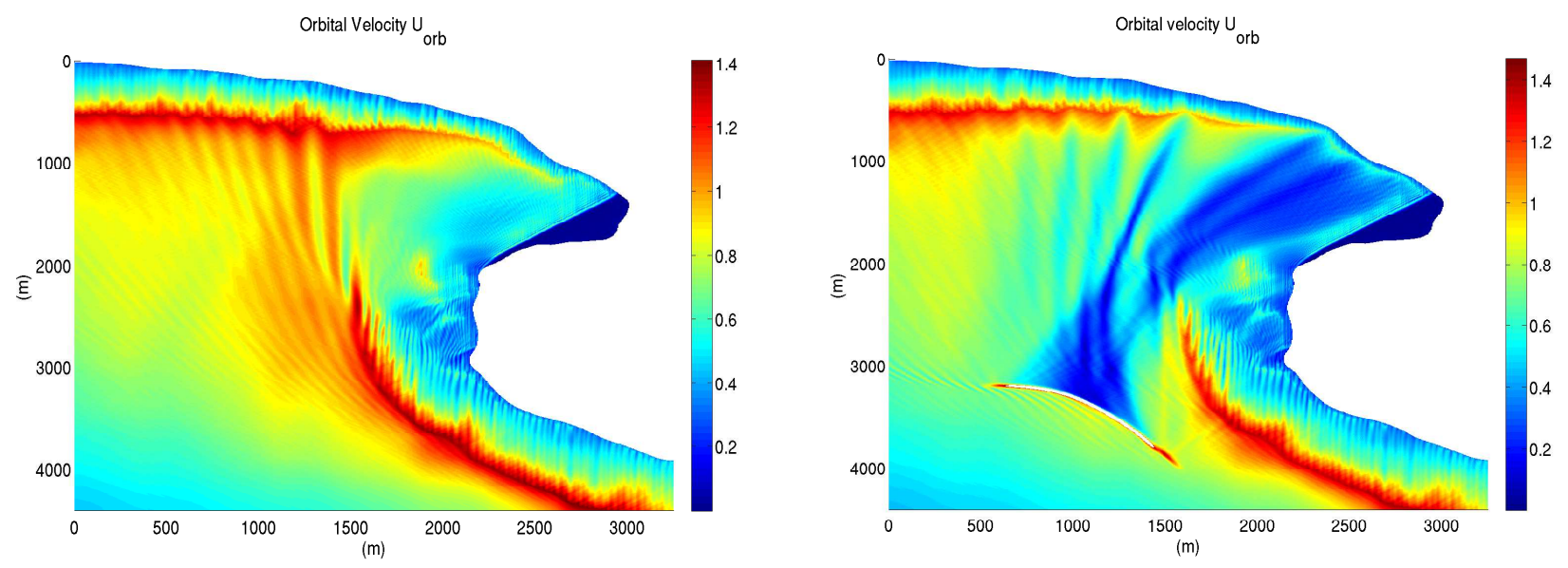

Figure 11: The bottom orbital velocity in the domain: (Left) for the initial configuration, (Right) for the optimized configuration.
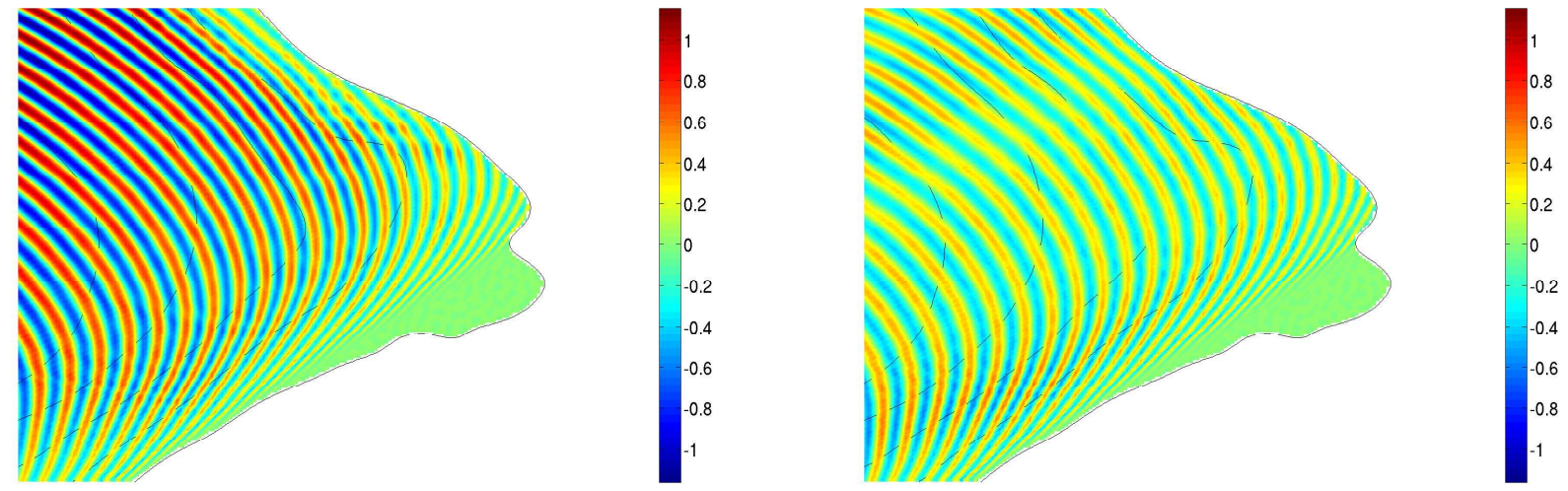

Figure 12: The free surface elevation in the cost function region $D$ : (Left) for the initial configuration, (Right) for the optimized configuration. 